\title{
A Case of Erythema Elevatum Diutinum (EED) Exhibiting A Keloid-Like Appearance
}

\author{
Bint-e Awan (D) · Yoshihiro Noda • Yuto Yabuno · Yu Hokazono • \\ Shinichi Ansai · Rei Ogawa
}

Received: August 4, 2021 / Accepted: October 30, 2021 / Published online: November 14, 2021

(C) The Author(s) 2021

\begin{abstract}
Introduction: Most severe-appearing keloids tend to occur around joints because of the increased extensional stimulation of the scar in those areas. However, erythema elevatum diutinum (EED) appears more commonly on friction sites including extensor surfaces of the extremities and dorsal surfaces of joints. EEDs also presents as red-brown and elevated lesions. Case Presentation: In this report, we describe a 42-year-old female who presented with firm, sporadic, brown-colored raised nodules on her
\end{abstract}

B. Awan · Y. Noda · Y. Yabuno · Y. Hokazono R. Ogawa

Department of Plastic, Aesthetic and Reconstructive Surgery, Nippon Medical School, Tokyo, Japan

B. Awan $(\bowtie)$

George Washington University School of Medicine and Health Sciences, Washington, DC, USA

e-mail: bzawan@gwu.edu

S. Ansai

Department of Dermatology, Nippon Medical

School, Tokyo, Japan bilateral lower extremities. As the appearance of these nodules resembled keloids, resection of the affected area with subsequent radiation therapy was initiated. However, histopathologic examination performed after treatment revealed tuberous lesions in the dermis, increased wired collagen fibers, neutrophilic infiltrate with nuclear dust, and edematous endothelial cells in the small vessels. Consequently, the patient was later diagnosed with EED. Post-surgery, no recurrence or abnormal scars appeared.

Discussion: Whereas clinical findings of EED are similar to that of keloids, the mechanisms of the two conditions differ considerably, leading to varying management strategies. EEDs can be misdiagnosed as keloids on several grounds; they can both appear morphologically similar, exhibit as stiff lesions, demonstrate chronic inflammation of the reticular dermis, and appear anywhere on the body. The only definitive method of differentiating between the two is through histopathologic examination.

Conclusion: EED should be considered as one of the differential diagnoses for any patients presenting with keloid-like lesions on friction sites and biopsy should be performed prior to resection and radiotherapy.

Keywords: Erythema elevatum diutinum; Keloids; Abnormal scars; Nodules 


\section{Key Summary Points}

Erythema Elevatum Diutinum (EED) is a rare chronic inflammatory skin lesion that most commonly occurs on extensor surfaces

In histopathologic examinations of EED, significant fibrosis is apparent with rich neutrophilic infiltrate in the walls of the microvasculature

EEDs usually appear as plaques or papules but can morphologically appear and feel similar to keloids

When treating keloidal lesions on friction sites, EED should be considered as a possible diagnosis and biopsy should be performed before administering treatment

\section{INTRODUCTION}

Aberrant response to the wound-healing process can lead to formation of keloids, characterized by excessive collagen deposition and dysregulated growth [1]. Although keloids can manifest anywhere on the body, they tend to develop more severely around joints as one mechanism of keloid development is extensional stimulation of the scar [2]. In contrast, erythema elevatum diutinum (EED) is a rare type of vasculitis that appears more commonly on friction sites including extensor surfaces of the extremities and dorsal joints. They present as red-brown papules or plaques [3]. Although EEDs resemble keloids in their firmness upon palpation [4], their histopathologic characteristics are distinctive. In EED, significant fibrosis is evident with rich neutrophilic infiltrate in the walls of the microvasculature [5]. On the other hand, keloids demonstrate an invasive tumor-like growth in the papillary dermis with thickened but flattened epidermis, hyalinized collagen bundles in the dermis, and an obliterated papillary-reticular boundary [6]. Additionally, EED is most notably associated with streptococcal infections and has been linked to systematic diseases such as IgA gammopathy and hematologic abnormalities such as B-cell lymphoma $[7,8]$.

Herein, we report on a case of EED presenting in a keloid-like manner, and review aspects of the mechanisms of these dermatologic conditions.
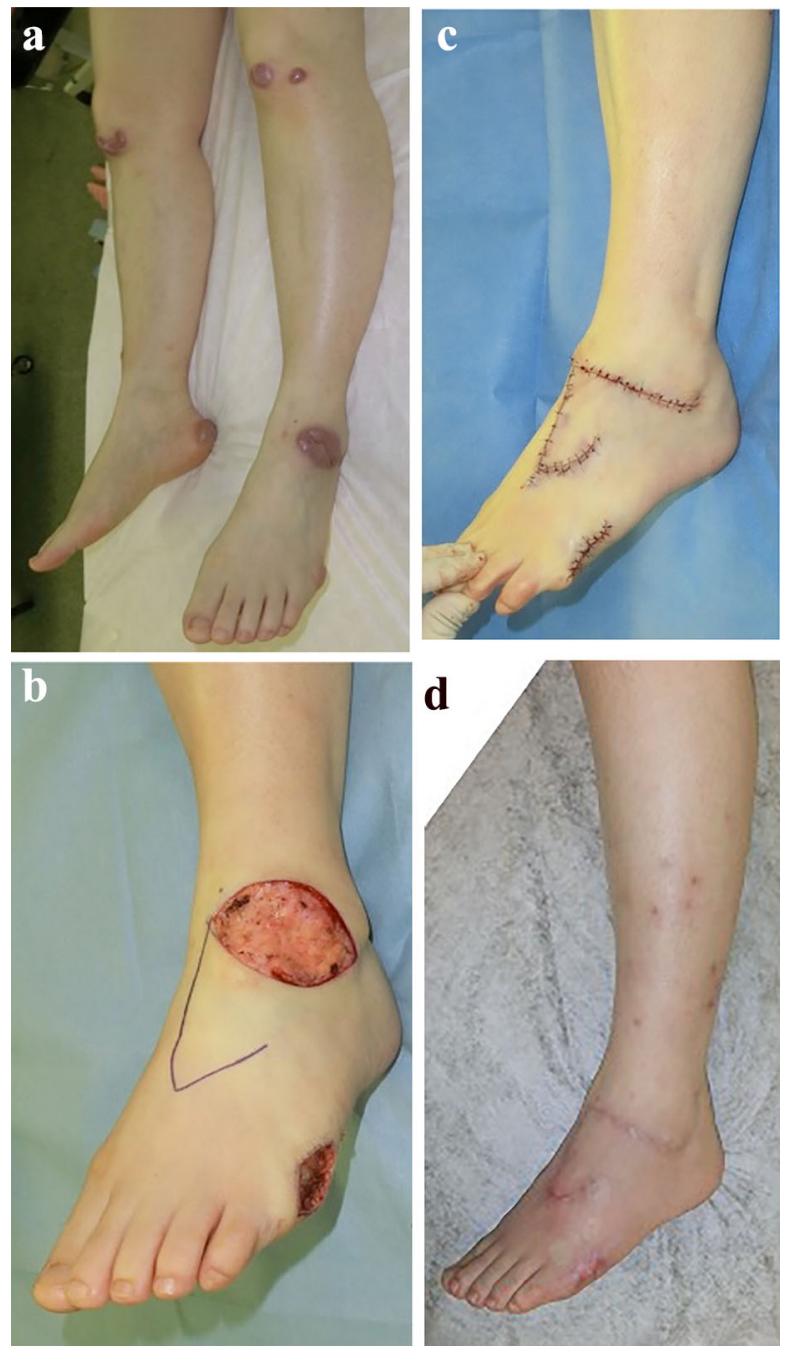

Fig. 1 (A) Preoperative view with the EED nodules on both knees, right tibial region, left dorsum of foot, right calcaneal area, and lateral side of the left foot. (B) Design of the local flap. (C) Immediately after surgery. (D) Six months postoperative view 


\section{CASE}

A 42-year-old woman presented with firm, brown-colored tumorous nodules on her bilateral lower extremities (Fig. 1). The patient started noticing the growths after sustaining some insect bites in these areas. The dermatologist she initially visited diagnosed her with keloids and subsequently treated her with triamcinolone injection and steroid tape. However, the patient did not respond to treatment, and the nodules did not soften or reduce in size. When she later visited our keloid specialty outpatient department in Nippon Medical School Hospital, the examination revealed dark brown-colored nodular lesions on bilateral knees, the right tibial region, dorsum of the left foot, the right calcaneal area, and the lateral side of the left foot (Fig. 1A). The nodules on her lower extremities manifested in one of two ways; the first type of nodule appeared very similar to keloids, but the other type was partially rounded in shape, unlike a usual keloid. Ultimately, the original diagnosis of keloids was reaffirmed and surgery along with radiation therapy was determined to be the best course of treatment. The nodules were resected under general anesthesia with subsequent administration of $18 \mathrm{~Gy} / 3$ fractions continuous radiation therapy. After the initial course of treatment, a biopsy was sent to pathology. The histopathologic examination revealed tuberous lesions in the dermis, increased wired collagen fibers, neutrophilic infiltrate with nuclear dust, and edematous endothelial cells in the small vessels (Fig. 2). Through these histologic findings, the patient was subsequently diagnosed with EED. Post-surgery, the patient reported no recurrence of EED or incidence of abnormal scar formation, including keloids or hypertrophic scars. The patient provided informed consent for the photographs and publication of this case report.

\section{DISCUSSION}

EED is a rare chronic inflammatory skin lesion first reported in 1880 by Hutchinson [9]. Although the etiologies of EED are not fully defined, it usually arises in the intertriginous areas of extensor surfaces of extremities and dorsal joints. Upon inspection and palpation, clinical findings are quite similar to that of keloids. Though EED-affected areas tend to be more reddish-brown or burgundy in color, and often morphologically appear as plaques or papules [10], their stiffness is analogous to that of keloids. The mechanisms of EED are not completely understood, but reports indicate an arthus-type immunologic reaction to an antigen with immune complex deposition in the cutaneous microvasculature [11], namely a type III hypersensitivity reaction, might be the root cause. As a result, histopathologic examination of EED lesions reveals a predominantly neutrophilic infiltrate with broken nuclei and significant fibrosis in the entire layer thickness of the dermis [4]. Keloids also originate from chronic inflammation of the reticular dermis, and this helps explain why these conditions may resemble each other [12].

When it comes to the treatment of EED, diaminodiphenyl sulfone is the drug of choice. The mechanisms of how this drug treats EED are not fully defined, but the current understanding is that it prevents neutrophilic accumulation in the dermal layer [4]. In addition, corticosteroids are used as second-line treatment [11]. Lastly, surgery for EED is another viable option in cases where the lesion can be resected through marginal excision and closed with normal dermal tissue [11]. For patients with IgA paraproteinemia who are refractory to other treatments, multiple studies have shown that intermittent plasma exchange can also help clear out flaresups of EED [4].

Keloids, on the other hand, are a type of abnormal scarring that can result from trauma and burns. Morphologically, these scars develop into reddish, stiff masses [8]. Usually, they are diagnosed only through clinical findings including the history, scar appearance, and palpation. The standard therapy for keloids in Japan, where this case was reported, includes steroid tape and injection, surgery, and postoperative radiation [13, 14]. Usually, keloid treatment, including adjuvant radiation therapy, tends to be implemented prior to any histopathologic examinations. Therefore, EED lesions that appear similarly to keloids have a 


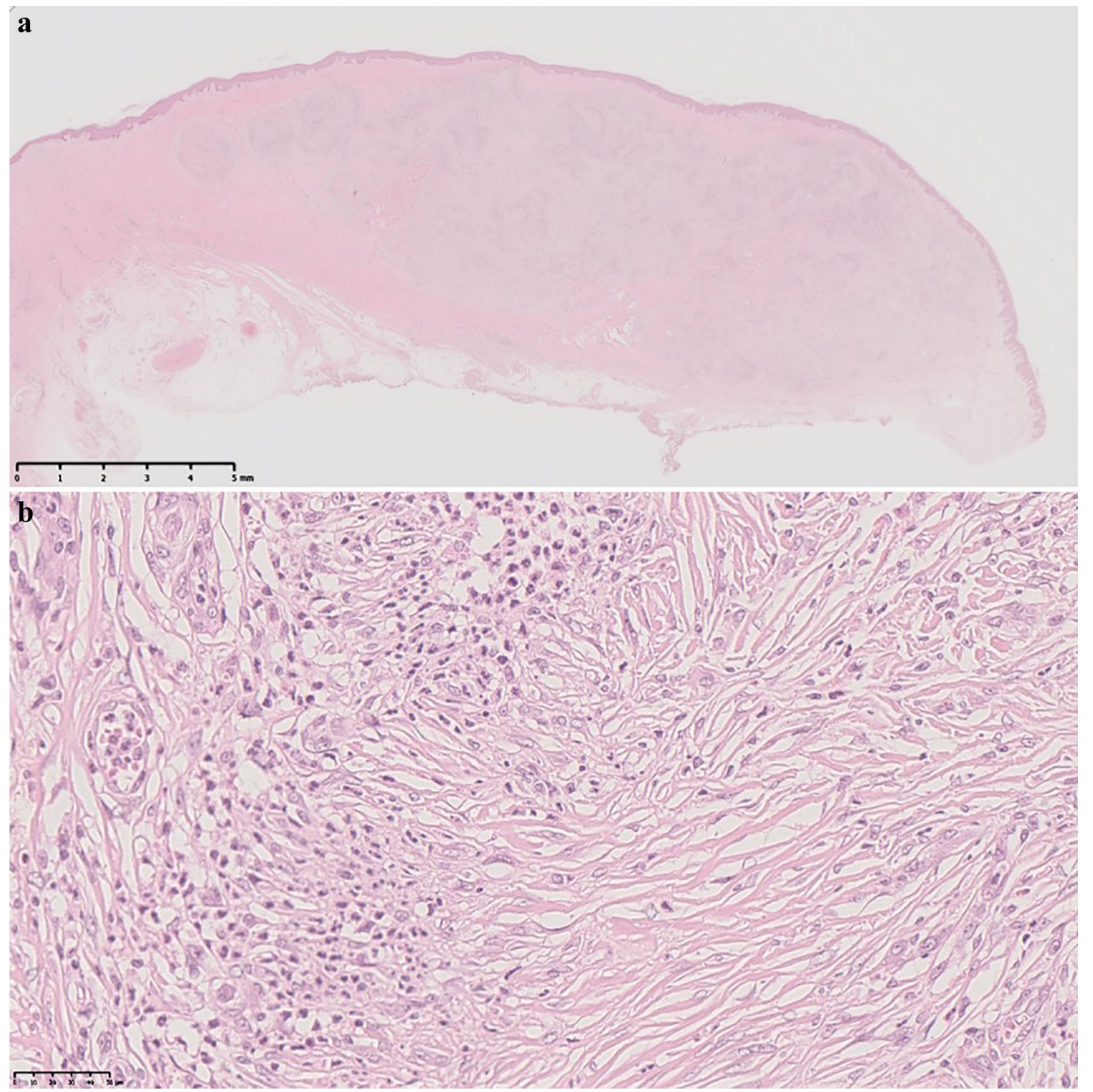

Fig. 2 Nodular lesions in the dermis. In the lesions, increasing characteristic wired collagen fibers, infiltration of neutrophils, and swelling of small endovascular cells are presented

high likelihood of being misdiagnosed and mismanaged as histologic assessment is the only way to accurately distinguish between them.

Though EED nodules are most commonly found on extensor and periarticular surfaces, and keloids most frequently arise on the chest, shoulders, earlobes, upper back, posterior neck, cheeks, and knees [15], both conditions can appear anywhere on the body. This characteristic further complicates the process of differentiating between them.

In the case reported here, the appearance of the patient's EED scars were judged to be quite similar to keloids on two specific grounds. First, the nodules' coloring was similar to that of keloids. Since EED and keloids both exhibit inflammation in the dermic layer [2, 3], they 
may both cause reddish pigmentation. Second, the protuberance of her scars gave them the appearance of keloids. Both conditions display as an increased thickness in the dermic layer $[2,3]$, without any significant changes in the epidermis. As such, EED lesions and keloids can not only appear morphologically similar, they can, in presenting with local inflammation, also demonstrate a similar clinical course $[2,3]$. Consequently, immunosuppressive therapy, such as steroid injection or tapes, can help shrink and soften the scars. According to current accepted practice guidelines in Japan, biopsy is not recommended before treatment for post-injury keloids diagnosed with high levels of certainty. As such, our patient's nodules were completely resected and treated with adjuvant radiation therapy. The patient showed an excellent response to this treatment and reported no recurrence or occurrence of abnormal scars in follow-up.

Remarkably, to our knowledge, only one other case of EED that clinically mimicked keloids has been reported in the literature [16]. In 2001, Krishnan et al. described a 53-year-old man presenting with enlarging tumorous nodules over his legs, feet, arms, hand, and back. However, their patient had more extensive lesions on his body compared to the patient in this report.

\section{CONCLUSION}

Diagnosing cutaneous manifestations simply through clinical findings might have its merits as the most cost and time effective method of diagnosis. However, there are instances where further investigation is necessary for accuracy, and this was the case with the patient discussed in this report. Our study suggests that, when treating keloidal lesions on friction sites, EED should be considered as a possible diagnosis, and a biopsy should be performed for confirmation before administering treatment. By the same token, this report indicates that the medical field could benefit from an inquiry into the mechanism of mass formations of EED nodules that morphologically appear similar to keloids.

\section{ACKNOWLEDGEMENTS}

We thank the participants of this study.

Funding. No funding or sponsorship was received for the publication of this study.

Authorship. All named authors meet the International Committee of Medical Journal Editors (ICMJE) criteria for authorship for this article, take responsibility for the integrity of the work as a whole, and have given their approval for this version to be published.

Author Contributions. All authors take responsibility for the integrity of the work as a whole, and have given final approval to the version to be published.

Disclosures. Bint-e Awan, Yoshihiro Noda, Yuto Yabuno, Yu Hokazono, Shinichi Ansai, and Rei Ogawa have nothing to disclose.

Compliance with Ethics Guidelines. While the institutional review board approval was not required for this single case study, the patient provided consent for publication of this report.

Data Availability. All data generated or analyzed during this study are included in this published article as supplementary information files.

Open Access. This article is licensed under a Creative Commons Attribution-NonCommercial 4.0 International License, which permits any non-commercial use, sharing, adaptation, distribution and reproduction in any medium or format, as long as you give appropriate credit to the original author(s) and the source, provide a link to the Creative Commons licence, and indicate if changes were made. The images or other third party material in this article are included in the article's Creative Commons licence, unless indicated otherwise in a credit line to the material. If material is not included in the article's Creative Commons licence and your intended use is not permitted by statutory regulation or exceeds the permitted use, you will need to obtain permission directly from the 
copyright holder. To view a copy of this licence, visit http://creativecommons.org/licenses/bync/4.0/.

\section{REFERENCES}

1. Berman B, Maderal A, Raphael B. Keloids and hypertrophic scars: pathophysiology, classification, and treatment. 2017;S3-18. https://doi.org/10. 1097/DSS.0000000000000819

2. Sano H, Hokazono Y, Ogawa R. Distensibility and gross elasticity of the skin at various body sites and association with pathological scarring: a case study. J Clin Aesthetic Dermatol. 2018;11:15-8.

3. Sardina LA, Jour G, Piliang MP, Bergfeld WF. Erythema elevatum diutinum a rare and poorly understood cutaneous vasculitis: a single institution experience. J Cutan Pathol. 2019;46:97-101. https://doi.org/10.1111/cup.13378.

4. Momen SE, Jorizzo J, Al-Niaimi F. Erythema elevatum diutinum: a review of presentation and treatment. J Eur Acad Dermatol Venereol. 2014;28: 1594-602. https://doi.org/10.1111/jdv.12566.

5. Mancano VS, Dinato SLME, Almeida JRP, Romiti N. Erythema elevatum diutinum. An Bras Dermatol. 2018;93:614-5.

6. Jumper N, Paus R, Bayat A. Functional histopathology of keloid disease. 2015;30:1033-57. https://doi.org/10.14670/HH-11-624

7. Bolognia JL, Braverman IM. Skin manifestations of internal disease. In: Jameson J, Fauci AS, Kasper DL, Hauser SL, Longo DL, Loscalzo J, editors. Harrison's principles of internal medicine. 20th ed. McGraw Hill; 2018.

8. Ogawa R, Akaishi S, Kuribayashi S, Miyashita T. Keloids and hypertrophic scars can now be cured completely: recent progress in our understanding of the pathogenesis of keloids and hypertrophic scars and the most promising current therapeutic. Strategy. 2016;83:46-53. https://doi.org/10.1272/jnms. 83.46 .

9. Hutchinson J. On two remarkable cases of symmetrical purple congestion of the skin in patches, with induration. Br J Dermatol. 1880;1:10.

10. Wahl CE, Bouldin MB, Gibson LE. Erythema elevatum diutinum: clinical, histopathologic, and immunohistochemical characteristics of six patients. Am J Dermatopathol. 2005;27:397-400.

11. Ahmad S, Delarosa M, Kleinman W, Ahmad R. Primary surgical treatment of erythema elevatum diutinum. J Hand Surg. 2019;44:522.e1-522.e5.

12. Ogawa R. Keloid and hypertrophic scars are the result of chronic inflammation in the reticular dermis. 2017;18. https://doi.org/10.3390/ ijms18030606

13. Ogawa R, Akita S, Akaishi S, Aramaki-Hattori N, Dohi T, Hayashi T, et al. Diagnosis and treatment of keloids and hypertrophic scars-japan scar workshop consensus document 2018. 2019;7:39-019-0175-y. (eCollection 2019). https://doi.org/10.1186/ s41038-019-0175-y

14. Ogawa R, Dohi T, Tosa M, Aoki M, Akaishi S. The Latest strategy for keloid and hypertrophic scar prevention and treatment: the Nippon Medical School (NMS) Protocol. 2021;88:2-9. https://doi. org/10.1272/jnms.JNMS.2021_88-106

15. Arno AI, Gauglitz GG, Barret JP, Jeschke MG. Up-todate approach to manage keloids and hypertrophic scars: a useful guide. 2014;40:1255-66. https://doi. org/10.1016/j.burns.2014.02.011

16. Krishnan RS, Hwang LY, Tschen JA, Subrt P, Hsu S. Erythema elevatum diutinum mimicking extensive keloids; quiz 386. Cutis. 2001;67:381-5. 